\title{
Apropriação de conceitos matemáticos na Educação Infantil
}

\author{
Appropriation of mathematical concepts in Pre-school
}

\author{
Maria Auristela Barbosa Alves de Miranda \\ Antônio Villar Marques de Sá
}

\begin{abstract}
Resumo: Este artigo objetiva analisar o processo de apropriação de conceitos matemáticos na Educação Infantil. Fundamentado na Teoria Histórico-Cultural, apresenta um panorama teórico do objeto e a análise de dois episódios vividos em pesquisa de Doutorado ainda em curso que utilizou como instrumentos dinâmicas conversacionais e observação participante na jornada de um Centro de Educação Infantil, tendo como sujeitos uma professora e dez crianças de 5 anos de idade. Concluímos que: 1) as crianças se encontram no processo de apropriação de conceitos matemáticos e os vivenciam, mas não têm a informação de que se tratam de conceitos matemáticos; 2) é fundamental o papel da professora na apresentação dos conceitos, posto que a apropriação da cultura se faz nas relações sociais; 3) o processo de apropriação da cultura matemática não se faz em aulas, mas a partir dos campos de experiências propostos pela Base Nacional Comum Curricular (BNCC).
\end{abstract}

Palavras-chave: Campos de experiências. Conceitos matemáticos. Currículo da Educação Infantil. Educação Infantil. Teoria Histórico-Cultural.

\begin{abstract}
This article aims to analyze the process of appropriating mathematical concepts in Pre-school. Based on the Cultural-Historical approach, it present here a theoretical overview of our object and the analysis of two episodes experienced in ongoing $\mathrm{PhD}$ research it used as instruments conversational dynamics and participant observation of interactions in a day of a Pre-school Institution. The subjects of study were a teacher and ten five-year-old children. We concluded that: 1) children are in the process of appropriating mathematical concepts and experience them, but do not have the information that those are mathematical concepts; 2 ) the teacher's role in presenting the concepts is fundamental, since the appropriation of culture takes place in social relations; 3 ) the process of appropriation of mathematical culture is not done in classes, but based on the fields of experience proposed by Base Nacional Comum Curricular (BNCC).
\end{abstract}

Maria Auristela Barbosa Alves de Miranda Doutoranda em Educação. Professora da Secretaria de Estado de Educação do Distrito Federal. Distrito Federal, Brasil. (iD) orcid.org/0000-0003-0665-6409 $\bowtie$ auristelamaria@gmail.com

Antônio Villar Marques de Sá Doutor em Ciências da Educação. Professor do Programa de Pós-Graduação em Educação da Universidade de Brasília (UnB). Distrito Federal, Brasil. iD orcid.org/0000-0001-8815-9216 $\bowtie$ villar@unb.br

Recebido em 30/06/2020 Aceito em 20/09/2020 Publicado em 16/10/2020

Keywords: Fields of experience. Mathematical concepts. Curriculum of Early Childhood Education. Child education. Cultural-Historical approach.

\section{Introdução}

Este artigo, fruto de pesquisa de Doutorado em andamento, tem por objetivo analisar 0 processo de apropriação de conceitos matemáticos na Educação Infantil à luz da Teoria HistóricoCultural. Análise engendrada na necessidade de compreender as relações dialéticas presentes 
nas seguintes constatações: 1) Na escola da infância se dá grande ênfase aos processos de apropriação da cultura escrita (SOUZA e MELLO, 2017) e se discute bastante sobre a alfabetização nessa etapa da Educação, enquanto as aprendizagens matemáticas e científicas ficam relegadas a segundo plano; 2) Ainda é comum a fragmentação entre os saberes, dessa forma as professoras e os professores nem sempre compreendem que a apropriação dos saberes da Matemática, da Ciência, da Arte, da Filosofia favorecem a apropriação da cultura escrita; posto que as crianças são seres de totalidade, não divisíveis, portanto aprendem e se desenvolvem de modo integral e não em aspectos separados; 3) Existe uma disputa entre teorias que defendem 0 ato de ensinar (ou instruir) na Educação Infantil e outras que defendem a não diretividade nos espaços de educação não domésticos (ARCE, 2013).

Neste artigo, analisamos essa temática à luz da Teoria Histórico-Cultural e de documentos normativos da Educação Infantil no Brasil: Diretrizes Curriculares Nacionais para a Educação Infantil — DCNEI (BRASIL, 2010) e Base Nacional Comum Curricular — BNCC (BRASIL, 2017).

Para iniciar a conversa, trazemos a memória histórica do atendimento aos bebês e crianças pequenas e sua constituição como Educação Infantil, discorrendo sobre suas especificidades e currículo, para, então, determo-nos sobre a apropriação de conceitos e, em particular, os matemáticos nas experiências cotidianas da escola da infância. Por fim, apresentamos o delineamento da pesquisa, trazendo resultados e conclusões.

Ensejamos que este artigo contribua para o pensar e o fazer de profissionais que atuam na escola da infância e que suscite a ampliação da temática com o entendimento de que, segundo a Teoria Histórico-Cultural, constituímos nossa humanidade à medida que nos apropriamos da cultura humana produzida no curso da história. Portanto, de acordo com Magalhães et al. (2017), os bebês, crianças bem pequenas e crianças pequenas têm direito a essa cultura.

Assim como, na primeira etapa da Educação Básica, esse direito se materializa não por meio de aulas ministradas, mas de experiências colaborativas intencionalmente planejadas pelas professoras ou professores às quais as crianças atribuem sentido. E que a educação tem como objetivo promover o desenvolvimento integral da criança e não apenas o aspecto cognitivo, assim, o sujeito apropria-se de conceitos matemáticos para se constituir humanamente, não apenas para ser inteligente. 


\section{A escola da infância: breve memória histórica}

Tendo anunciado que analisaremos o processo de apropriação de conceitos matemáticos na Educação Infantil à luz da Teoria Histórico-Cultural, é imprescindível demarcar o que aqui entendemos por apropriação e traçar um breve desenho do que seja a Teoria Histórico-Cultural e, na sequência, lançar o olhar para a história e pensar de onde veio a Educação Infantil e como tem se constituído, não linearmente, mas entre contradições, avanços e retrocessos, como primeira etapa da Educação Básica. A história é produzida pelos seres humanos e cada época tem características específicas que influenciam a tomada de decisões e, por conseguinte, as políticas para as infâncias e seu atendimento.

A Teoria Histórico-Cultural surgiu, no início do século XX, da necessidade de delineamento de uma Psicologia embasada no Materialismo Histórico-Dialético e, segundo Vigotski (2003), deveria se constituir como uma Psicologia Pedagógica, pois a educação é fundamental para a construção do homem novo (ARCE, 2004), proposta pela revolução russa de 1917.

Essa teoria entende a educação como um processo colaborativo no qual há um triplo protagonismo: da professora ou professor, que intencionalmente proporciona experiências promotoras de desenvolvimento; do estudante, no nosso caso a criança, que participa ativamente do processo, como sujeito e não passivamente; e da cultura, que deve ser apropriada pela criança e pela professora ou professor também, pois a todo momento seguimos nos apropriando mais e mais da cultura, nas relações colaborativas.

No entendimento de Mello (2015), a principal contribuição dessa teoria para a educação consiste nas discussões sobre quem é o ser humano, como ele aprende e se desenvolve. Para ela, o ser humano constitui sua humanidade por meio do desenvolvimento das qualidades especificamente humanas, aquilo que Vigotski chama de funções psicológicas superiores ou culturais, entre as quais o pensamento abstrato, a memória lógica, a atenção voluntária, a formação de conceitos, a autorregulação. Para a Teoria Histórico-Cultural, essas funções são a princípio primárias ou elementares, muito ligadas aos instintos, mas a partir do processo de educação tornam-se superiores (ou culturais), mais refinadas.

Quanto ao conceito de apropriar-se, nessa teoria ultrapassa o entendimento de aquisição ou aprendizagem. Segundo Leontiev (2004, p. 340), "a criança não se adapta ao mundo dos objetos e fenômenos humanos que a rodeiam, fá-lo seu, isto é, apropria-se dele". Significa, portanto, que a pessoa, ao apropriar-se da cultura, a incorpora; esta passa a pertencer, fazer parte 
da forma de ver, compreender e agir sobre o mundo. Por isso, apropriar-se da cultura geral "acumulada pela humanidade é um passo fundamental para a criança tornar-se humana" (ARCE, 2013, p. 31), e apropriar-se de conceitos matemáticos, em particular, não significa apenas ampliar os conhecimentos nesta área, mas ampliar a experiência humana.

Partindo da ideia de que a experiência de educação sistematizada, intencionalmente planejada e vivida como processo colaborativo é essencial para a constituição da pessoa humana, passemos agora à retomada histórica da escola da infância.

Desde o ano de 1996, a Lei de Diretrizes e Bases da Educação Nacional (LDB-EN), Lei n ${ }^{0}$ 9.394/96 (BRASIL, 1996), instituiu a Educação Infantil como primeira etapa da Educação Básica, ofertada em creches (para crianças de 0 a 3 anos e 11 meses) e pré-escolas (para crianças de 4 anos a 5 anos e 11 meses). Todavia, é importante verificar que creches e pré-escolas se originaram em contextos e com objetivos diversos.

A creche surgiu e se difundiu na Europa, impulsionada pela revolução industrial e ingresso das mulheres no mercado de trabalho, em fins do século XVIII e início do XIX. No Brasil, segundo Kuhlmann Jr. (2015), em 1879 fora publicado um artigo intitulado "A creche" (asilo para a primeira infância), em que se apresentava a preocupação com os bebês nascidos após a lei do ventre livre. Posteriormente à inauguração da primeira creche, em 1899, no Rio de Janeiro, como filantropia dos empregadores (objetivo assistencialista) para a prole dos operários da Companhia de Fiação e Tecidos Corcovado, essas instituições espalharam-se em condições precárias, como depósitos de bebês e crianças pequenas.

A pré-escola, no Brasil, nasceu como Jardim de Infância, inspirado no Kindergarten, sistema educacional criado em 1839 por Fröbel na Alemanha. Destinava-se ao atendimento de crianças de 3 anos a 7 anos de idade, entendidas como plantinhas que precisavam ser tratadas amorosamente pelas jardineiras (professoras), e por meio de jogos ou brinquedos (os famosos dons $^{1}$ ) receber formação religiosa, cuidados com o corpo, observação da natureza, passeios, exercícios de desenho, canto, poesia.

Com a promulgação da Constituição Federal (BRASIL, 1988), considerada a "Constituição Cidadã", ampliou-se o olhar sobre os direitos. A carta magna inaugurou a ideia de educação como direito de todas as pessoas, portanto, de bebês e crianças também. Para além do direito das

\footnotetext{
1 De acordo com Arce (2004, p. 15), Fröbel chamava de dons os "brinquedos criados para auxiliar a brincadeira infantil sem ferir seu desenvolvimento natural".
} 
famílias, especialmente das mulheres, as próprias crianças têm direito de frequentar a escola da infância. Assim, oito anos depois, a LDB (BRASIL, 1996) apresentou a Educação Infantil como primeira etapa da Educação Básica, afirmando a impossibilidade de separar cuidado e educação.

A LDB (BRASIL, 1996) organizou a Educação Infantil em dois períodos: Creche para crianças de 0 a 3 anos e 11 meses de idade e Pré-escola para crianças de 4 anos a 5 anos e 11 meses. Embora tendo unificado as duas esferas (creche e pré-escola) em uma mesma etapa (Educação Infantil), a manutenção dos termos precisa ser problematizada uma vez que os nomes são carregados de sentidos e, embora as DCNEI (BRASIL, 2010) tenham apresentado as especificidades da etapa, no imaginário social a creche ainda traz a conotação de cuidado e a préescola de preparação para a escola, para a alfabetização.

Tendo sido apontada como primeira etapa da Educação Básica, a Educação Infantil guarda especificidades que a distinguem das demais etapas. Vejamos a seguir o que dizem as DCNEI (BRASIL, 2010) acerca dessas especificidades.

\section{Especificidades da Educação Infantil e seu currículo}

As DCNEI (BRASIL, 2010) trouxeram o entendimento de que o currículo na escola da infância não apresenta conteúdos a serem trabalhados, organizados em disciplinas ou áreas do conhecimento. $O$ que não significa abandonar a criança aos seus conhecimentos prévios, a suas teorias provisórias. Nesta etapa da Educação, currículo é o conjunto de práticas que buscam articular os saberes e experiências que as crianças trazem da vida cotidiana com os conhecimentos que foram produzidos ao longo da história da humanidade, que fazem parte do patrimônio cultural, artístico, ambiental, científico e tecnológico a fim de promover seu desenvolvimento integral (BRASIL, 2010, 2017).

Essa ideia vai ao encontro da afirmação de Vigotski (2014, p. 109): "a aprendizagem da criança começa muito antes da aprendizagem escolar. A aprendizagem escolar nunca parte do zero. Toda a aprendizagem da criança tem uma pré-história". Portanto, compete à escola da infância articular esses conhecimentos e promover a ampliação dos conceitos do cotidiano rumo à apropriação dos conceitos científicos.

Segundo as DCNEI (BRASIL, 2010), na Educação infantil a professora ou professor não ministra aulas, mas proporciona experiências colaborativas por meio das quais as crianças se 
apropriam do patrimônio cultural, artístico, científico, tecnológico, ambiental. Essa concepção de Educação Infantil se coaduna com a Teoria Histórico-Cultural que, na busca de compreender e explicar o processo de formação humana, concebe os profissionais da educação como intelectuais cuja função é colocar ao alcance das crianças o conhecimento historicamente produzido pela humanidade, organizar vivências que oportunizem a compreensão do mundo e as relações sociais; estimular a ação coletiva, a solidariedade e a cooperação entre as pessoas; contribuir para que as crianças aprendam a pensar, falar, ouvir, criticar, argumentar e "posicionar-se de modo crítico e sensível" (TEIXEIRA e BARCA, 2017, p. 31).

Fica, pois, normatizado que na escola da infância não há espaço para o ensino transmissivo nem ao abandono à vivência do cotidiano sem a ampliação e apropriação da cultura. As crianças aprendem e se desenvolvem por meio das interações e brincadeiras (BRASIL, 2010, 2017), não abandonadas a si mesmas, ao contrário, as professoras e os professores têm a responsabilidade de coordenar o processo de planejamento colaborativo das ações, a clareza na intencionalidade educativa com que propõem as experiências que devem ser vividas com fins a promover o desenvolvimento integral das crianças e não apenas o aspecto cognitivo.

Pensando dessa forma, pode parecer abstrato, mas o desenho dessa organização curricular se encontra também nos documentos norteadores da Educação Infantil. O parecer do Conselho Nacional de Educação (CNE), Câmara de Educação Básica (CEB) n. 20/2009 (BRASIL, 2009, p. 16) já indicava que "a organização curricular da Educação Infantil pode se estruturar em eixos, centros, campos ou módulos de experiências que devem se articular em torno dos princípios, condições e objetivos propostos nesta diretriz". Assim, em 2017 foi indicado que "a organização curricular da Educação Infantil na BNCC está estruturada em cinco campos de experiências" (BRASIL, 2017, p. 38).

\section{A Educação Infantil organizada em campos de experiências}

No ano de 2017, depois de uma vasta discussão acerca do que se chamaria de Base Nacional Comum Curricular, que apresentasse o que é básico para cada criança brasileira se apropriar no território nacional e, a partir disso, cada unidade da Federação complementar com suas especificidades, o documento foi aprovado pelo Conselho Nacional de Educação.

A BNCC (BRASIL, 2017) para a Educação Infantil apoiou-se nas DCNEI (BRASIL, 2010), mantendo a impossibilidade de separar as ações de educar e cuidar, reafirmando como eixos 
norteadores das práticas pedagógicas as interações e a brincadeira, reiterando a concepção de criança como sujeito histórico e de direitos, que observa, questiona, levanta hipóteses, faz julgamentos, apropria-se dos saberes produzidos e sistematizados ao longo da história humana; enfatizando a necessidade de imprimir intencionalidade educativa às práticas no cotidiano da escola da infância.

Todo o currículo para a Educação Infantil se apoia nos direitos de aprendizagem e desenvolvimento: conhecer-se, conviver, brincar, explorar, expressar-se e participar. Direitos esses que devem se materializar por meio dos campos de experiências. "Os campos de experiências constituem um arranjo curricular que acolhe as situações e as experiências concretas da vida cotidiana das crianças e seus saberes, entrelaçando-os aos conhecimentos que fazem parte do patrimônio cultural" (BRASIL, 2017, p. 40).

Dessa forma, por meio de experiências intencionalmente planejadas pela professora ou professor, com a participação e colaboração das crianças, a estas é possibilitada a apropriação da cultura humana. Falamos em possibilidade porque, para a Teoria Histórico-Cultural, a relação que se estabelece entre a criança, a professora ou professor e a realidade social, que Teixeira e Barca (2017, p. 36) chamaram de "situações de ensino-aprendizagem", impulsionam, mas não trazem garantia ou certeza de desenvolvimento.

Essas situações são, pois, organizadas em cinco campos de experiências definidos pela BNCC (BRASIL, 2017): O eu, o outro e o nós; Corpo, gestos e movimentos; Traços, sons, cores e formas; Escuta, fala, pensamento e imaginação; e Espaços, tempos, quantidades, relações e transformações. A ideia do documento encontra convergência com a Teoria Histórico-Cultural pois, de acordo com Vigotski (2014, p. 108), "a tarefa do docente consiste em desenvolver não uma única capacidade de pensar, mas muitas capacidades particulares de pensar em campos diferentes". Segundo essa teoria, a pessoa se desenvolve como uma totalidade, não fragmentada e assim deve ser o processo de apropriação da cultura.

A BNCC (BRASIL, 2017) defendeu que esses campos não devem ser trabalhados como disciplinas escolares, com dia e hora determinados para cada um, mas ao contrário, que as experiências vividas colaborativamente na escola da infância levem em conta diversos saberes conjugando os que a criança já traz com aqueles do patrimônio cultural da humanidade. $E$, de fato, não é fácil pensar em uma proposta que se complete em um único campo. Assim, quando pensamos na apropriação de conceitos matemáticos, certamente estabelecemos ligação com 
Espaços, tempos, quantidades, relações e transformações, mas essa vivência não se encerra neste campo.

Organizar, pois, o currículo em campos de experiências favorece o entendimento do ser humano como um ser integral, indivisível e que também se apropria da cultura de uma forma integral, não fragmentada, bem como que essa apropriação visa não apenas ao desenvolvimento cognitivo, mas à própria constituição como ser humano. Discorramos, então, sobre a formação de conceitos segundo a Teoria Histórico-Cultural e como ela pode se desenvolver na escola da infância.

\section{Formação de conceitos à luz da Teoria Histórico-Cultural}

Para Vigotski (2012a), a capacidade de pensar por conceitos se concretiza na adolescência; porém, as bases que conduzem a esse desenvolvimento se estabelecem ainda na primeira infância. A esse respeito, Zaporozhets (1986) defendeu que crianças de 5 e 6 anos de idade são capazes de refletir logicamente em ações materiais intelectuais em atividades de colaboração orientadas por um adulto. De acordo com Solovieva, Rosas-Rivera e Quintanar-Rojas (2017, p. 323), "o trabalho na zona de desenvolvimento proximal significa a introdução de novos conhecimentos, que se tornam acessíveis para a criança em situação de colaboração coletiva".

Zona de desenvolvimento proximal é um conceito de grande importância na Teoria Histórico-Cultural porque é onde a professora ou professor deve atuar. Segundo Vigotski (2012b), existem dois níveis de desenvolvimento: o real e o potencial. O real é aquele que já foi conquistado, o que a pessoa consegue realizar com autonomia, o que ela já sabe; o desenvolvimento potencial é aquilo que ela poderá fazer em breve e que não é ilimitado, por exemplo, um bebê de quatro meses não pode realizar a marcha nem mesmo com a colaboração de um adulto. Entre esses dois níveis de desenvolvimento, encontra-se a zona de desenvolvimento proximal, ou seja, aquilo que a pessoa ainda não consegue sozinha, mas o faz com ajuda.

É nessa zona que a professora e o professor devem trabalhar, pois propor ao estudante uma atividade que não lhe desafia, que ele já aprendeu, não faz sentido e não desperta o interesse, além do que, para Vigotski (2012b), o desenvolvimento acontece quando a pessoa aprende algo, quando surge algo novo, que ele chamou de neoformação, isto é, o resumo de todo 0 desenvolvimento psíquico em um dado período que reestrutura toda a personalidade da criança, que modifica o seu papel nas relações sociais que vivencia. Convém lembrar que nem toda 
aprendizagem gera desenvolvimento, por exemplo, aprender a dar o laço no sapato não modifica a situação da criança no seu grupo, mas aprender a falar promove essa mudança radical.

Segundo essa teoria, o processo educacional ocorre sempre como uma ação colaborativa. Uma vez que compreende a constituição humana como apropriação da cultura que se faz nas relações com outros seres humanos, mediadas por signos e instrumentos, assim como por entender que o ser humano é, desde o nascimento, um ser social, que os processos psíquicos todos surgem duas vezes: primeiramente no plano social e depois no plano individual (internalização). Assim, a pessoa nunca está sozinha, mesmo que desacompanhada, psiquicamente sua constituição está interligada, é influenciada e influencia os outros membros da sua família, do seu grupo, da sua comunidade. Então, a educação é entendida como ação colaborativa em que dois sujeitos do processo colaboram um com o outro e se apropriam, embora em níveis diversos, da cultura. Esta não é apropriada de uma vez por todas porque, sendo histórica e social, encontra-se em constante movimento.

Ainda para Vigotski (2012a), a apropriação dos conceitos ocorre - como qualquer outra aprendizagem - a partir da necessidade. A pessoa aprende porque tem necessidade de aprender e a constituição dessa necessidade nasce na relação entre a atividade da pessoa que aprende (esta nunca é passiva), a intencionalidade da pessoa que a instrui, orienta sua aprendizagem (a professora ou professor que planeja e propõe colaborativamente) e a cultura (objeto de apropriação pela pessoa).

É importante enfatizar que "não existe um desenvolvimento da infância universal, único e natural" (ARCE, 2004, p. 17), antes, o desenvolvimento infantil é fortemente ligado aos processos educativos, às condições sociais, econômicas, culturais e históricas. Dessa forma, a necessidade não é algo espontâneo, natural e imutável. Cabe à professora ou professor, nas ações colaborativas, ajudar para que a criança sinta necessidade de aprender algo novo.

O ato de aprender, de pensar por conceitos é importante nessa teoria não para que a pessoa seja mais inteligente, mas porque essa forma amplia o desenvolvimento integral da pessoa. Vigotski (2012a) apontou dois tipos de conceitos: os do cotidiano, que ele chamou de espontâneos, e os científicos, cuja educação sistematizada desempenha um papel primordial no seu desenvolvimento. Esse desenvolvimento se dá em três níveis diferentes: sincrético, pensamento por complexos e pensamento por conceitos.

O pensamento sincrético é característico da criança pequena, quando se observa uma 
dependência daquilo que captam seus olhos e percebe os objetos diversos como um amontoado inseparável. Qualquer objeto pode ser agrupado em qualquer conjunto, uma vez que as imagens sincréticas se baseiam nos vínculos emocionais e subjetivos da criança em relação aos objetos.

O segundo estágio é o pensamento por complexos, em que a criança começa a unificar objetos homogêneos em grupos comuns, ou seja, a pensar de modo mais coerente e objetivo, embora ainda dependente da experiência imediata. Assim, Vigotski (2012a) identificou que por vezes a criança inclui um objeto no conjunto em razão da semelhança física entre eles, em razão de um atributo (cor, forma, tamanho), ou formando coleções com objetos que não se repitam no conjunto.

No pensamento por conceitos, os objetos são generalizados por um traço, um vínculo essencial e uniforme entre os objetos. Essa fase se caracteriza pelas operações mentais de generalização, análise e síntese. 0 pensamento abstrato permite que as operações se realizem no plano lógico-verbal e não mais no concreto-visual.

Convém ainda lembrar que, na Teoria Histórico-Cultural, quando falamos em níveis não nos referimos a crescimentos puramente quantitativos, mas sobretudo qualitativos, ou seja, é a qualidade da função, sistema ou atividade que importa mais. Assim como ao falar em estágios não o fazemos pensando na linearidade, mas nas características que se apresentam, e mesmo indicando um período etário este é sempre aberto, como referência, não como limite estanque nem sequencial.

Para Vigotski (2012a), essas diferentes etapas por que passa o sujeito na atividade de formação de conceitos continuam a coexistir. Mesmo os adultos não pensam sempre por conceitos genuínos, mas em alguns aspectos do cotidiano continuam a pensar em complexos ou pseudoconceitos.

Vigotski (2012a) não menosprezava a importância dos conceitos do cotidiano. Ao contrário, considerava-os a base sobre a qual se assentam os conhecimentos científicos e estes geram possibilidades para novos conhecimentos do cotidiano. A diferença essencial entre os conhecimentos do cotidiano e os científicos consiste no fato de que os primeiros são construídos empiricamente, pela observação da vida diária, enquanto que os conhecimentos científicos se formam por meio de ações mediadas, pois são "resultado de um processo de ensino sistemático e organização pelo professor, envolvendo maior abstração, generalização e operações mentais" (MORAES et al., 2017, p. 365). 
As operações lógicas, as simbólicas e as numéricas são necessárias à formação de conceitos e à realização de atividades matemáticas (SOLOVIEVA, ROSAS-RIVERA e QUINTANAR-ROJAS, 2017). Embora não se concretizem na idade pré-escolar, lá se encontram as bases do pensamento teórico; por isso, é necessário que sejam trabalhadas nessa fase, com ações intencionais e colaborativas da professora ou professor. O problema é que muitas dessas atividades são propostas por meio de exercícios de repetição, adaptação e memorização sem reflexão de situações lógicas, o que não cria zona de desenvolvimento proximal.

Portanto, para a Teoria Histórico-Cultural, a criança não cria conceitos sozinha, mas aprende, por meio das relações sociais, mediadas por instrumentos e signos, os conceitos de sua comunidade (particular) e da humanidade (universal) e passa a utilizá-los como seus (apropriase), formando uma maneira de pensar e agir sobre o mundo, com as características culturais de sua comunidade; um processo ao mesmo tempo social e singular. Entre esses conceitos, estão os matemáticos.

\section{Apropriação de conceitos matemáticos na escola da infância}

De acordo com a Teoria Histórico-Cultural, a criança é um sujeito não fragmentado, não divisível, não sendo possível separar o desenvolvimento físico do emocional, do cognitivo, do atencional, do moral, do volitivo. Da mesma forma a BNCC (BRASIL, 2017) orienta que as crianças na escola da infância se apropriam da cultura humana a partir de campos de experiências, que são inter-relacionados. Embora discutamos em específico a apropriação de conceitos matemáticos, buscamos as relações no sentido de não fragmentar 0 ser humano, nem 0 patrimônio cultural da humanidade, nem as experiências vividas na escola da infância.

É, pois, conveniente pensar na apropriação de conceitos matemáticos - na sua preparação e gênese - desde a Educação Infantil com o intuito de empreender esforços no sentido de superar a grande dificuldade e ineficiência que as crianças têm apresentado ao longo de vários anos nessa área. Rosa e Galdino (2017, p. 330), analisando pesquisas realizadas entre 2012 e 2016 no Brasil, assim como os resultados da Avaliação Nacional de Alfabetização (ANA) de 2014, concluíram que "a maioria dos estudantes brasileiros permanece nos limites do conhecimento empírico".

No entanto, isso se constitui como um grande desafio. Para além das limitações na formação (inicial ou continuada) das professoras e professores habilitados para atuação na 
Educação Infantil, segundo Moraes et al. (2017), ainda se discute muito sobre quais conhecimentos matemáticos devem ser compartilhados na pré-escola. Todavia, não se trata de defender uma Educação Matemática pragmática e utilitarista, com o propósito de instrumentalizar as crianças à resolução de problemas descontextualizados ou que não façam sentido para elas, nem de antecipar conhecimentos e experiências no campo da Matemática específicos do Ensino Fundamental, mas, tomando como referência a Teoria Histórico-Cultural, colaborar no processo de apropriação do patrimônio cultural da humanidade, do qual a Matemática faz parte.

Moraes et al. (2017, p. 362) apontaram que na escola da infância as crianças precisam e têm 0 direito de se apropriar das bases dos conceitos matemáticos, "tais como controle das diferentes quantidades, grandezas, espaço e formas em sua relação direta com o adulto e com os instrumentos, físicos e simbólicos". Nesse sentido, é indispensável que a professora ou professor proporcione experiências que possibilitem compreender semelhanças, diferenças, de interioridade, de distância, noções de topologia, estabelecendo relações imprescindíveis para a apropriação dos conceitos matemáticos.

Partindo da Teoria Histórico-Cultural, compreendemos o sujeito em sua totalidade, assim, no momento em que desenvolve a atenção, desenvolve, também, a memória, a emoção, a cognição e todos os demais aspectos. Apropriar-se de conceitos matemáticos implica, pois, no seu desenvolvimento como ser humano integralmente.

Essa forma de entender a Matemática vincula-se à ideia de educação como prática humanizadora, ou seja, para a Teoria Histórico-Cultural, os seres humanos se humanizam a partir da educação e as instituições coletivas têm um papel primordial nesse processo. Isso é a apropriação cultural, por meio dos instrumentos e signos, tomar para si as Artes, a Ciência, a Matemática, os esportes, a Filosofia, as tecnologias e toda a produção do trabalho dos humanos que vieram antes, no sentido de pertencimento a essa comunidade humana e com a responsabilidade de ampliá-la e deixá-la como herança melhorada aos que virão.

Convém acrescentar que, para Moraes et al. (2017), a Matemática é um instrumento simbólico potencializador do pensamento humano; por isso, os conceitos matemáticos devem ser apresentados não de maneira isolada, mas no contexto de um sistema conceitual, a partir das relações entre grandezas, reflexões sobre contagem, adição e multiplicação, na interconexão das significações geométricas, algébricas e aritméticas (ROSA e GALDINO, 2017), acessando a história de como esses conceitos surgiram no curso da humanidade. 
Desde que nascem, as crianças estão inseridas em um universo matemático, convém que sejam introduzidas, na escola da infância, na sistematização desses saberes; pois, como temos discutido, a Teoria Histórico-Cultural compreende o processo de humanização a partir da apropriação da cultura, um dos produtos culturais é exatamente a Matemática, que surgiu da necessidade das pessoas de resolverem as situações da vida cotidiana.

Entendemos, portanto, que a apropriação dos conhecimentos matemáticos não se dá de maneira natural ou intuitiva; mas, a partir da mediação dos instrumentos e signos culturais, por meio das relações entre seres humanos. Entendendo também que o papel da escola da infância é imprescindível, propusemo-nos a investigar como ocorre o processo de apropriação de conceitos matemáticos na Educação Infantil.

\section{Percurso metodológico}

Conforme anunciamos na introdução, este artigo se configura como um recorte de pesquisa em andamento no curso de Doutorado na Faculdade de Educação da Universidade de Brasília. Nossa proposta metodológica, em coerência com a teoria que sustenta a pesquisa, pressupõe as produções humanas como históricas e sociais. Essa coerência é indispensável, posto que Vigotski (2012b), o fundador da Teoria Histórico-Cultural, defendia que novos problemas científicos conduzem a novos métodos e técnicas de investigação.

Para essa teoria, que se embasa no Materialismo Histórico-Dialético, o método encerra três categorias fundamentais: a totalidade (a realidade pesquisada não é vista fragmentada em partes), a mediação (a cultura é apropriada nas relações entre seres humanos por meio de instrumentos e signos) e a contradição (por ser histórica, a realidade não segue um fluxo linear, mas um movimento contínuo que abrange avanços e retrocessos).

Na busca de compreender a totalidade, as mediações e contradições que explicam nosso objeto, com apoio na Teoria Histórico-Cultural, nossa pesquisa empírica realizou-se em um Centro de Educação Infantil da rede pública do Distrito Federal, em uma turma de Segundo Período (crianças de 5 anos de idade).

Contamos como participantes (sujeitos ativos nas relações sociais) dez crianças de uma turma de 5 anos de idade e sua professora. Esta assinou o Termo de Consentimento Livre e Esclarecido, assim como os familiares das crianças. Estas assinaram Termo de Assentimento e 
escolheram seu pseudônimo com o qual foram identificadas na pesquisa.

Por se tratar de pesquisa realizada à luz da Teoria Histórico-Cultural, optamos pelo uso do termo construção de informações em lugar de coleta de dados apoiados em González-Rey (2010), para quem o conhecimento se legitima em um processo, não se trata de criar expectativas de conhecer a realidade tal como é, pois a realidade se constitui de sujeitos - pesquisadora e pessoas ativas que recebem, compartilham e colaboram com a pesquisa - em relação. Dessa forma, cremos que as informações não estão no campo à espera de serem colhidas; antes, foram construídas nas interações entre os sujeitos singulares da pesquisa: pesquisadora e sujeitos participantes.

Assim, empregamos como instrumentos de construção de informações as observações de 16 jornadas de atendimento (cinco horas cada) na Educação Infantil, entrevista e dinâmicas conversacionais (GONZÁLEZ-REY, 2010) com a professora e dinâmicas conversacionais com as crianças, algumas mediadas por desenho ou por livro de literatura infantil.

Para o presente recorte, objetivamos analisar o processo de apropriação de conceitos matemáticos na Educação Infantil à luz da Teoria Histórico-Cultural. Realizamos a análise de dois eventos vivenciados durante a pesquisa empírica, um deles a partir do instrumento de observação, o outro a partir do instrumento de dinâmicas conversacionais com as crianças. As análises das construções de informações construídas empiricamente se deram ancoradas na Teoria HistóricoCultural. Na sequência, vejamos o que apontamos como resultados.

\section{Discussão dos resultados}

Analisamos a seguir dois eventos ocorridos durante a pesquisa empírica, o primeiro deles por meio do instrumento de observação e o segundo por meio de dinâmicas conversacionais com as crianças.

Ambos os eventos mostram a importância do papel da professora na apresentação dos conceitos científicos, que não surgem de maneira natural na vida das crianças, mas mediados pela cultura. O primeiro que selecionamos ocorreu no mês de junho de 2019, a partir do instrumento de observação das interações na jornada da turma.

A professora falou: "Hoje, 24, é dia de São João. A gente vai rever o que viu desde fevereiro, março, abril, maio e junho". Pegou uma série de cartelas em que estavam registrados a 
representação de números e suas quantidades, animais e versos rimados. Começou a mostrar, uma por vez, às crianças. Lia os versos e interagia com as crianças. Iniciou pelo zero e foi até 0 número 10.

Professora: 0 que é zero?

Crianças: Não tem nada.

Para o número 1, a gravura apresentava um galo escondido atrás de uma moranga. A professora perguntou:

Professora: Quem é o marido da galinha? 0 macho, quem é?

Crianças: 0 galo.

Professora: Como o galo faz?

Crianças: Cocoricó.

Para o número 2:

Professora: 0 que são vacas leiteiras?

Crianças: Vacas que dão leite.

Professora: Depois do 2, quem vem?

Crianças: 03.

Professora: Os personagens agora fazem qua-qua-qua.

Crianças: Patos.

A professora pediu que algumas crianças contassem.

Chaves: Uma, duas, três.

Professora: São patos, é um, dois, três.

Para cada número, a professora convidava a observar o número, contar os desenhos e realizar o desenho da escrita do número no ar. Para o 3 falou: "Parece o $B$, só que não tem o tracinho".

0 texto do número quatro perguntava quem seria o primeiro pintinho a chegar. A professora perguntou à turma quem seria o primeiro. Perguntou também 0 que 0 pintinho estava usando.

Crianças: Patinete.

Professora: Patinete não. Patinete é aquele que a gente empurra com o pé. 0 que ele tá usando?

Crianças: Patins.

Mostrando o número quatro na gravura, a professora diz: "Esse 4 é diferente do nosso". E mostra para as crianças o numeral que costumam grafar, comparando com esse, de imprensa.

Rememorou: "Quem estava no número 3? E no 2? E no 1?

Antes de apresentar o numeral 5, a professora alertou: "Esse animal faz ronc-ronc".

Crianças: Porcos.

Professora, fazendo o desenho no ar: Reto, desci, barrigão.

Como dica para introduzir o próximo cartão, a professora falou: "Agora vem aquele animal que a gente conta quando vai dormir". 
Crianças: Ovelha, carneiro.

No verso, falava-se em lentilhas, a professora então explicou que lentilha parece feijão. No desenho no ar, fez a comparação com o número 9, dizendo que bastava inverter para que o desenho representasse 09 .

Professora: Quem vem agora? Já foi o 1, o 2, 0 3, 0 4, 05 e 0 6. E agora?

Crianças: 07.

A professora mostrou o cartão e as crianças disseram: Carneiro.

Professora: É uma cabra, mas parece um carneiro mesmo.

Ao ler o verso, perguntou: 0 que é pança?

Crianças: Barriga, encher a pança.

Chaves: Igual o Seu Barriga².

Professora: 07 parece que número?

Crianças: 0 número 1.

Pikachu chamou a atenção da professora ao fazer o desenho no ar. A professora valorizou, parabenizou.

0 cartão do número 8 tinha cavalos. A professora, após ler os versos, convidou as crianças a fazerem o som do galope. Fizeram batendo os pés no chão, em seguida, ela os convidou a fazerem o barulho batendo com as mãos nas pernas. Então conduziu a intensidade: "Depressa. Devagar. Parei".

Ao conduzir o desenho no ar do numeral, lembrou que algumas pessoas fazem uma bolinha em cima, outra bolinha embaixo, mas chamou a atenção de que esse número parece o $\mathrm{S}$ do sapo. Orientou: faz o S, virou, encontra a ponta lá em cima.

Antes de mostrar o cartão do número 9, falou: A fêmea é a vaca e o macho, quem é? Crianças: 0 boi.

Professora: O boi, mas muito bravo. Quem é o boi bravo?

Crianças: 0 touro.

Professora: Parece 06 , mas a bolinha é para cima.

Flash não fez o desenho no ar junto com a turma, então a professora o convidou a fazer. Ele disse que não sabia. Ela falou: Vamos, faz o círculo e desce. Ele fez com ela.

Antes de mostrar o cartão do número 10, começou a cantar: "Um ratinho bonitinho que fazia qui-qui-qui" e a turma cantou junto. Convidou a turma a contar a quantidade de ratinhos na gravura, a contar nos dedos. Revisou os animais que haviam aparecido em cada número.

Analisamos que o processo de apropriação de conceitos matemáticos na Educação Infantil se faz tendo em vista o triplo protagonismo defendido pela Teoria Histórico-Cultural: do sujeito que planeja e propõe ações pedagógicas intencionais, do sujeito que se apropria da cultura nas relações sociais, e da cultura, que deve ser apropriada (fazer parte da vida do sujeito).

\footnotetext{
2 Personagem do desenho animado "A turma do Chaves", pelo qual a turma tinha grande apreço e com frequência fazia referências.
} 
Reiteramos que a Teoria Histórico-Cultural, alicerce da nossa pesquisa, compreende que a capacidade de pensar por conceitos científicos se sedimenta no período da adolescência, mas se inicia desde a primeira infância e necessita da intervenção intencional educativa.

A professora não convidou a turma para uma aula de Matemática, mas, por meio de uma atividade de mediação de leitura de versos, mobilizou saberes diversos. Em nossa análise, a atividade que realizou com as crianças teve a intencionalidade de ampliar os conhecimentos das crianças, para além dos números e quantidades, que eram os temas centrais. Conversou com as crianças sobre as flexões de gênero do substantivo: galo e galinha, vaca e boi, cabra e carneiro; informou o que é patinete, o que é lentilha, o que significa a palavra leiteira, a diferença entre boi e touro; explorou com as crianças os sons produzidos pelos animais: galo, pato, porco, cavalo; mobilizou informações do cotidiano infantil presentes em contos e filmes: 0 animal que contamos antes de dormir; permitiu a fala coletiva e individual das crianças - algumas vezes as respostas se davam em coro, em outros momentos a atenção se voltava para uma criança em particular.

Nesse episódio analisamos estratégias diversificadas utilizadas pela professora para ajudar as crianças a se apropriarem da representação numérica e suas quantidades: a visualização nos cartões, a contagem nos dedos, o desenho ou escrita dos números no ar, a comparação de sua escrita com letras $(3 / \mathrm{B}, 8 / \mathrm{S})$ ou outros números $(6 / 9,7 / 1)$, a comparação do registro manuscrito com o de imprensa do número 4 , a instrução verbal sobre a escrita $(3,8,9)$.

Visualizar é importante porque, de acordo com Vigotski (2012a), inicialmente 0 pensamento da criança se apoia no que vê. Durante os períodos de sincretismo e de complexos o pensamento da criança busca apoio nos vínculos visuais-concretos.

A estratégia de desenhar no ar encontra justificativa no pensamento de Mello e Bissoli (2015, p. 142), segundo o qual, antes de se apropriar da escrita, a criança exercita e desenvolve as representações pelos gestos, desenhos e brincadeira de faz de conta, "embora cada uma dessas formas de expressão possua uma história própria, todas elas guardam entre si um elemento comum que prepara o caminho para a escrita: pouco a pouco se transformam em representações simbólicas ou signos".

As atividades de comparar, chamar a atenção das crianças para perceberem semelhanças e diferenças, favorecem o desenvolvimento do pensamento por complexos, descrito por Vigotski (2012a) e característico dessa faixa etária, quando as crianças começam a perceber vínculos e estabelecer relações entre os objetos e não o fazem espontaneamente, mas em colaboração com 
outros seres humanos.

Acerca da instrução ou orientação verbal, esta é uma das estratégias de ajuda descritas por Vigotski (2012a): a professora ou professor pode mostrar um modelo de ação para que a criança imite; mostrar uma parte da ação para que a criança complemente; realizar a ação junto com a criança; orientar a ação verbalmente; propor a colaboração de um coetâneo.

Analisamos ainda que a atividade proposta pela professora não se limitou a um campo de experiências (BRASIL, 2017). Tendo a centralidade nos conceitos matemáticos, que estariam associados diretamente ao campo Espaços, tempos, quantidades, relações e transformações, 0 desenho do numeral no ar se inscreve no campo Corpo, gestos e movimentos, assim como a expressão corporal e vocalização dos sons produzidos por eles; ao explorar versos, palavras e suas letras iniciais, a atividade ganhou matizes do campo Escuta, fala, pensamento e imaginação; a alternância dos turnos de fala promove aspectos ligados ao campo $\mathrm{O}$ eu, o outro e o nós. Enfim, conforme temos discutido, as experiências ocorrem relacionadas a diversos campos, assim como o desenvolvimento da criança acontece de maneira multilateral.

O segundo episódio que aqui analisamos aconteceu em meio às dinâmicas conversacionais, no mês de maio de 2019.

Pikachu: Eu tenho um irmão e duas irmãs, indicando a estatura de cada um no seu próprio corpo (todos menores que ele).

Pikachu: Tenho também um cachorro e um periquitinho. Ele é gigante.

Pesquisadora: 0 que é gigante?

Ele respondeu mostrando com as mãos abertas, na distância das extremidades de seu tronco.

Pikachu: 0 cachorro é metade lobo.

Pesquisadora: Como metade lobo?

Pikachu: É porque ele faz assim "auuuuuuuuuuuu", de vez em quando.

Pikachu: Meu periquitinho é metade Flash.

Pesquisadora: 0 que é metade?

Pikachu: É metade, metade de bolinhas.

Pikachu conversou com a pesquisadora utilizando referências a tamanho (gigante), quantidades (um irmão, duas irmãs, um periquito, um cachorro, metade), embora sem saber explicar ao certo. Quando perguntado sobre o que é gigante, Pikachu não soube falar a respeito, mas mostrou o comprimento com as mãos. Perguntado sobre o que é metade, também não utilizou 
um conceito ou definição.

Segundo Vigotski (2012a), no processo de formação de conceitos, antes de conseguir explicá-lo, a pessoa o utiliza (a ação vem antes do pensamento por conceito), faz uma descrição, ela sabe, mas não consegue definir. Daí a necessidade de que o professor ajude a criança a ampliar seus saberes, articular os conhecimentos do cotidiano com os científicos e se apropriar da cultura.

Dessa forma, analisamos que as crianças usam conceitos matemáticos no seu cotidiano: quantidades (ainda que por vezes representando com os dedos em vez de falando) e tamanhos, embora não convencionais (gigante) e indicados usando como parâmetro o corpo humano. De acordo com a Teoria Histórico-Cultural, as crianças são capazes e cabe à professora ou professor identificar e atuar na zona de desenvolvimento proximal no sentido de ofertar ajuda, colaboração, quando a criança ainda não consegue realizar a ação sozinha. Portanto, elas podem usar as expressões corretas, os nomes das coisas, pois, "quando a criança, com suas perguntas, consegue apoderar-se dos nomes dos objetos que a rodeiam, já está inserida numa etapa específica de aprendizagem" (VIGOTSKI, 2014, p. 110).

Portanto, urge superar a realidade em que as crianças vivem, mas não falam sobre Matemática na escola da infância. Elas têm o direito de serem instrumentalizadas para falar, conceituar aquilo que vivem. Isso vai ao encontro da afirmação de Duhalde e Cuberes (1998), de que as pesquisas revelam a presença da Matemática na pré-escola, todavia, denunciam a falta de uma apresentação explícita desses conceitos. Assim, as crianças usam informações sobre formas e dimensões; realizam a contagem de pessoas e objetos; comparam grandezas; mas, muitas vezes, sem se darem conta de que são conceitos matemáticos e sem utilizarem os termos adequados.

É, pois, seu direito saber que círculo é diferente de bola, que quadrado não é sinônimo de caixa, que a palavra tijolo não substitui o nome retângulo. Nossa defesa vai no sentido de que, por meio dos campos de experiências (BRASIL, 2017), os conhecimentos produzidos ao longo dos séculos pela humanidade sejam apropriados pelas crianças, não em disciplinas ou áreas do conhecimento, mas conectados, como de fato procederam suas origens. Todos esses saberes surgiram da necessidade de solucionar problemas do cotidiano e assim deve acontecer na vida da criança que deles se apropria. 


\section{A título de conclusão}

Trazemos como conclusões que as crianças se encontram no processo de apropriação de conceitos matemáticos e os vivenciam, mas não recebem a informação de que se tratam de conceitos matemáticos. Elas têm o direito de saber. $O$ fato de o currículo da Educação Infantil não estar organizar em disciplinas, não elencar conteúdos de áreas específicas do conhecimento não significa que as crianças não tenham o direito de saber que a cultura humana engloba saberes chamados de matemáticos, biológicos, químicos, físicos, linguísticos, musicais, tecnológicos e assim por diante.

Também fica evidente o quão fundamental é o papel da professora ou do professor na apresentação dos conceitos, posto que a apropriação da cultura se faz nas relações sociais. Para a Teoria Histórico-Cultural, a apropriação dos conceitos não é natural, mas fundamentalmente um processo mediado. Daí a inquestionável função da professora e do professor de, intencionalmente, propor atividades que impulsionem o desenvolvimento integral das crianças.

Outra conclusão possível, e relacionada com a abordada no parágrafo anterior, é a descoberta de que o processo de apropriação da cultura matemática não se faz em aulas, mas a partir dos campos de experiências propostos pela BNCC (BRASIL, 2017). Para a Teoria HistóricoCultural, as novas gerações têm o direito de se apropriar da cultura humana da forma como esta foi produzida, ou seja, a partir da necessidade. Assim, é fundamental que a professora ou 0 professor compreenda (ou desperte) a necessidade das crianças para se apropriar dos conceitos, e isso se dá na vida. E no cotidiano não é possível viver ora matemática, ora história, ora geografia, ora português; mas, acontecem simultaneamente, mesmo que haja o predomínio de um aspecto.

As crianças têm direito de se apropriar dos conceitos matemáticos assim como de todo 0 patrimônio cultural produzido pelos seres humanos no curso da história não com fins a saber Matemática ou ficar mais inteligentes, mas porque a apropriação da cultura humana amplia as qualidades especificamente humanas (VIGOTSKI, 2012b). Essa apropriação é assegurada como direito das crianças e não em aulas organizadas em disciplinas, mas em campos de experiências, em conjunto com diversos outros saberes (BRASIL, 2017).

Assim como, para a Teoria Histórico-Cultural (VIGOTSKI, 2014, 2018), a escola desempenha um importante papel no ato de compartilhar com as novas gerações o patrimônio cultural produzido e sistematizado no curso da história humana. A apropriação da cultura não se faz espontaneamente, mas a partir de experiências planejadas e vivenciadas colaborativamente, 
em que sujeitos que sabem coisas diferentes compartilham esses saberes e ampliam suas qualidades humanas.

Concluindo, apontamos alguns desafios com os quais nos defrontamos na pesquisa. Primeiramente, a busca de coerência com a teoria que elegemos como esteio. Tendo esta uma visão de totalidade monista (anti-dicotômica, não fragmentada em partes), constantemente precisamos estar atentos na busca de superação da tradicional dualidade cartesiana com que costumamos olhar o mundo e fazer ciência. Constituiu-se como outro desafio, o exercício de entender o currículo da Educação Infantil organizado em campos de experiências, por ser algo novo, estamos todos ainda em processo de apropriação.

Com este artigo, ensejamos, em particular, ampliar as discussões acerca da apropriação dos conceitos matemáticos, a partir dos campos de experiências, a fim de possibilitar às crianças a apropriação da cultura humana. E no geral, contribuir com a (re)afirmação das especificidades da Educação Infantil, como primeira etapa da Educação Básica, cujo propósito é o desenvolvimento integral das crianças e não apenas o cognitivo nem a preparação para a alfabetização ou o ingresso no Ensino Fundamental.

Desejamos, ainda, instigar outras pesquisas e discussões no campo da Educação Infantil organizada em campos de experiências. Por ser uma proposta nova (a BNCC foi aprovada em 2017), ainda estamos aprendendo como fazê-lo.

\section{Referências}

ARCE, Alessandra. 0 jogo e o desenvolvimento infantil na teoria da atividade e no pensamento educacional de Friedrich Froebel. Cadernos Cedes, Campinas, v. 24, n. 62, p. 9-25, abr. 2004.

ARCE, Alessandra. O Referencial Curricular Nacional para a Educação Infantil e o espontaneísmo: (re)colocando o ensino como eixo norteador do trabalho pedagógico com crianças de 4 a 6 anos. In: ARCE, Alessandra; MARTINS, Lígia Márcia. Quem tem medo de ensinar na Educação Infantil? Em defesa do ato de ensinar. Campinas: Alínea, 2013, p. 13-38.

BRASIL. Lei nº. 9.394, de 20 de dezembro de 1996. Estabelece as Diretrizes e Bases da Educação Nacional. Brasília: Diário Oficial da União, 23 dez. 1996.

BRASIL. Ministério da Educação. Conselho Nacional de Educação. Câmara de Educação Básica. Parecer CNE/CEB n. 20, de 11 de novembro de 2009. Revisão das Diretrizes Curriculares Nacionais para a Educação Infantil. Brasília: Diário Oficial da União, 9 dez. 2009.

BRASIL. Ministério da Educação. Secretaria de Educação Básica. Base Nacional Comum Curricular. Brasília: MEC/SEB, 2017. 
BRASIL. Ministério da Educação. Secretaria de Educação Básica. Diretrizes Curriculares Nacionais para Educação Infantil. Brasilia: MEC, 2010.

BRASIL. Presidência da República. Casa Civil. Constituição da República Federativa do Brasil de 1988. Brasília: Diário Oficial da União, 5 out. 1988.

DUHALDE, María Elena; CUBERES, María Teresa González. Encontros iniciais com a Matemática: contribuições à Educação Infantil. Tradução de Maria Cristina Fontana. Porto Alegre: Artes Médicas, 1998.

GONZÁLEZ-REY, Fernando Luis. Pesquisa qualitativa e subjetividade: os processos de construção da informação. São Paulo: Cengage Learning, 2010.

KUHLMANN JR., Moysés. Infância e Educação Infantil: uma abordagem histórica. Porto Alegre: Mediação, 2015.

LEONTIEV, Aleksei Nikolaevitch. O desenvolvimento do psiquismo. Tradução de Rubens Eduardo Frias. 2. ed. São Paulo: Centauro, 2004.

MAGALHÃES, Cassiana; GIROTTO, Cyntia Graziella Guizelim Simões; SILVA, Greice Ferreira da; MELLO, Suely Amaral. Planejando a ação docente para o máximo desenvolvimento da infância. In: COSTA, Sinara Almeida da; MELLO, Suely Amaral. Teoria Histórico-Cultural na Educação Infantil: conversando com professoras e professores. Curitiba: CRV, 2017, p. 219-230.

MELLO, Suely Amaral. Contribuições da Teoria Histórico-Cultural para a educação da primeira infância. Revista Cadernos de Educação, Pelotas, n. 50, p. 1-12, 2015.

MELLO, Suely Amaral; BISSOLI, Michelle de Freitas. Pressupostos da Teoria Histórico-Cultural para a apropriação da cultura escrita pela criança. Perspectiva, Florianópolis, v. 33, n. 1, p. 135160, jan./abr. 2015.

MORAES, Silvia Pereira Gonzaga de; ARRAIS, Luciana Figueiredo Lacanallo; MOYA, Paula Tamyris; LAZARETTI, Lucinéia Maria. O ensino de Matemática na Educação Infantil: uma proposta de trabalho com jogos. Educação Matemática Pesquisa, São Paulo, v. 19, n. 1, p. 353-377, 2017.

ROSA, Josélia Euzébio da; GALDINO, Ana Paula da Silva. Contribuições da Teoria HistóricoCultural para o ensino da Matemática nos Anos Iniciais. In: MORETTI, Vanessa Dias; CEDRO, Wellington Lima (Org.). Educação Matemática e a Teoria Histórico-Cultural: um olhar sobre as pesquisas. Campinas: Mercado das Letras, 2017, p. 329-353.

SOLOVIEVA, Yulia; ROSAS-RIVERA, Yolanda; QUINTANAR-ROJAS, Luis. Programa para solução de problemas como método para desenvolvimento de pensamento lógico em crianças escolares. In: MORETTI, Vanessa Dias; CEDRO, Wellington Lima (Org.). Educação Matemática e a Teoria Histórico-Cultural: um olhar sobre as pesquisas. Campinas: Mercado das Letras, 2017, p. 291-328.

SOUZA, Regina Aparecida Marques de; MELLO, Suely Amaral. O lugar da cultura escrita na educação da infância. In: COSTA, Sinara Almeida da; MELLO, Suely Amaral. Teoria HistóricoCultural na Educação Infantil: conversando com professoras e professores. Curitiba: CRV, 2017, p. $199-215$. 
TEIXEIRA, Sônia Regina; BARCA, Ana Paula de Araújo. Teoria Histórico-Cultural e Educação Infantil: concepções para orientar o pensar e o agir docentes. In: COSTA, Sinara Almeida da; MELLO, Suely Amaral. Teoria Histórico-Cultural na Educação Infantil: conversando com professoras e professores. Curitiba: CRV, 2017, p. 29-39.

VIGOTSKI, Lev Semionovitch. Aprendizagem e desenvolvimento intelectual na idade escolar. In: VIGOTSKI, Lev Semionovitch.; LURIA, Aleksandr Romanovitch; LEONTIEV, Aleksei Nikolaevitch. (Org.). Linguagem, desenvolvimento e aprendizagem. 12. ed. Tradução de Maria da Pena Villalobos. São Paulo: Ícone, 2014, p. 103-118.

VIGOTSKI, Lev Semionovitch. Obras escogidas - III - Problemas del desarrollo de la psique. Traducción de Lydia Kuper. Madrid: Antonio Machado, 2012b.

VIGOTSKI, Lev Semionovitch. Pensamiento y habla. Traducción de Alejandro Ariel González. Buenos Aires: Colihue, 2012a.

VIGOTSKI, Lev Semionovitch. Psicologia Pedagógica. Tradução de Claudia Schilling. Porto Alegre: Artmed, 2003.

VIGOTSKI, Lev Semionovitch. Sete aulas de L. S. Vigotski sobre os fundamentos da pedologia. Tradução e organização de Zoia Prestes e Elizabeth Tunes. Rio de Janeiro: E-papers, 2018.

ZAPOROZHETS, Alexander Vladimirovitch. Sellected psychological works. Moscou: Pedagogy, 1986. 